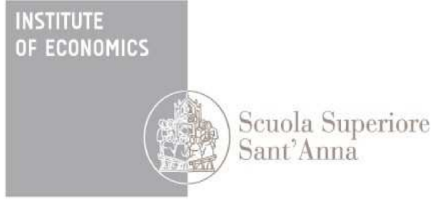

LEM | Laboratory of Economics and Management

Institute of Economics

Scuola Superiore Sant'Anna

Piazza Martiri della Libertà, 33 - 56127 Pisa, Italy ph. +3905088.33 .43$

institute.economics@sssup.it

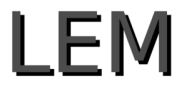

Working Paper Series

\title{
Estimating the elasticity of trade: the trade share approach
}

\author{
Mauro Lanati * \\ *Department of economics and management, University of Pisa, Italy
}




\title{
Estimating the elasticity of trade: the trade share approach
}

\author{
Mauro Lanati * \\ March 2013, revised April 2013
}

\begin{abstract}
Recent theoretical work on international trade emphasizes the importance of trade elasticity as the fundamental statistic needed to conduct welfare analysis. Eaton and Kortum (2002) proposed a two-step method to estimate this parameter, where exporter fixed effects are regressed on proxies for technology and wages. Within the same Ricardian model of trade, the trade share provides an alternative source of identication for the elasticity of trade. Following Santos Silva and Tenreyro (2006) both trade share and EK models are estimated using OLS and Poisson PML to test for the presence of heteroskedasticity-type-of-bias. The evidence from both specifications suggests that the bias in the OLS estimates significantly impacts the magnitude of trade cost elasticity. The welfare analysis reveals that the resulting extreme variability of the trade cost elasticity and the imposition of a common manufacturing share parameter for all countries generate substantial distortions in the calculation of benefits from trade.
\end{abstract}

JEL: F10, F11, F14

Keywords: trade cost elasticity; gravity model; competitiveness equation; trade share; gains from international trade

${ }^{*}$ Department of Economics and Management, University of Pisa. Email: mauro.lanati@ for.unipi.it. I am especially grateful to Prof. Keith Head for helpful comments and suggestions and to the SBE division of Sauder Business School for hosting me. I thank Prof.Fagiolo (Sant'Anna School of Advanced Studies) and Prof.De Benedictis (University of Macerata) for useful suggestions. 


\section{Introduction}

The elasticity of trade is a parameter which plays a key role in calculating the welfare gains from trade. Arkolakis et al. (2012) showed that within a particular class of trade models, the elasticity of trade and the share of expenditure on domestic goods are the only two parameters needed to calculate welfare gains from trade $1^{1}$ Since the import ratio is directly observable from the data, the estimation of the elasticity of trade becomes the key statistics for conducting welfare analysis.

The influential Eaton and Kortum (2002) article (henceforth EK) provides three different ways to estimate the elasticity of trade $\theta$, all derived from their Ricardian model of trade. The first method estimates $\theta$ by relating trade variation to a proxy for trade costs. As proxy for bilateral trade frictions they use the maximum price difference across goods between countries. This one-step methodology is based on a strong assumption: the price differences cannot be larger than trade costs. A method of moments estimator gives an elasticity of 8.28, which is the EK benchmark for welfare analysis.

The same proxy for trade costs has been used by EK in a second method for estimating $\theta$. This is again a one-step methodology where a transformed version of bilateral trade is regressed on the proxy of trade costs, importer and exporter fixed effects. In this alternative specification the proxy coefficient gives a measure of the elasticity of trade parameter. The geographic terms are used as instruments for the trade costs variable in a 2SLS analysis: they obtain an elasticity of 12.86 .

Simonovska and Waugh (2011) showed that these two methods lead to upward biased estimates of the elasticity of trade. To correct for this bias they propose a new simulated method of moments estimator. They apply their estimator to disaggregate price and trade-flow data for the year 2004. Their benchmark estimate for $\theta$ is 4.12, a measure which is less than a half of EK's preferred estimation.

\footnotetext{
${ }^{1}$ The trade models to which Arkolakis et al. conclusions apply are those models which feature the following assumptions: a) Dixit-Stieglitz preferences; b) one factor of production; c) linear cost functions; d) perfect or monopolistic competition along with three macro level restrictions i) trade is balanced; ii) aggregate profits are a constant share of aggregate revenues; and iii) the import demand system is CES. Among these models there are (besides the Armington model) Eaton and Kortum (2002), Krugman (1980) and variations and extensions of Melitz (2003) featuring pareto distributions of firm-level productivity.
} 
The third methodology to estimate trade elasticity employed in EK is a gravity based two-step procedure. EK provide a version of trade equation where a transformed bilateral trade variable is regressed on exporter technology and wages: they modify their original trade share expression until the price of intermediaries $p_{i}$ disappears from the final two-step equation. In this competitiveness equation the wage coefficient gives exactly a measure of the elasticity of trade $\mu_{w}=\mu_{t}=-\theta$. By instrumenting for wages their estimates yield an elasticity of 3.60. Simonovska and Waugh (2011) view this last EK estimate as reliable, since 3.60 is in line with their benchmark result.

Within the same EK Ricardian model of trade the original trade share expression can be viewed as an alternative competitiveness equation, in which bilateral imports are function of prices other than technology, wages and geographic barriers. As Head and Mayer (2013) pointed out, the key difference is that in the trade share expression the wage elasticity is $\mu_{w}=-\beta \theta$ whereas the trade elasticity is $\mu_{t}=-\theta$. Thus, by calculating the average labor share in gross manufacturing production in the sample, $\beta$, the effect of wage variation on estimated exporter fixed effects gives an alternative source of identication for trade elasticity.

This paper shows that in the EK two-step procedure the absence of bias in the first stage coefficients is crucial to obtain unbiased estimates of the trade cost elasticity parameter. Anderson and Yotov (2010b) argue that since the gravity system identifies only relative trade costs, their finding of a very high correlation between Poisson PML and the OLS estimates suggests that the two sets of coefficients are equally good proxies for the unobservable bilateral trade costs and can be used interchangeably in the calculation of important parameters such as multilateral resistances. The competitiveness equation, however, utilizes exporter fixed effects as dependent variable and a bias in the first stage estimations is likely to affect the outcome of the second step regression. With equally high correlation between Poisson PML and OLS estimates, the statistics show that the heteroskedasticitytype-of-bias of the OLS first stage results substantially affects the magnitude of the resulting trade elasticity parameter.

The paper is organized as follows. Section 2 outlines the EK model. Sections 3.1 and 3.2 illustrate some key definitions useful for a better understanding of the model and the data needed for the estimations. Section 3.3 describes the resulting econometric specifications and the estimation techniques employed in this analysis. Section 4.1 begins by replicating the EK two-step empirical analysis for 
1997. To check for heteroskedasticity-type-of-bias the first stage regressions are estimated using both OLS and Poisson PML. Section 4.2 contrasts the EK benchmark results with the trade share estimations. Section 5 is devoted to the welfare analysis, in particular it investigates how much the resulting variability of $\theta$ and the imposition of a common manufacturing share parameter impact the welfare gains from trade. Section 6 summarizes my findings.

\section{Model}

EK extend the two-country Dornbusch et al. (1977) Ricardian model of trade with a continuum of goods $j \in[0,1]$ to a world economy comprising $i=1,2, \ldots, N$ countries. The source of comparative advantage lies in countries differential access to technology, so that efficiency varies across countries and industries. An industry of country $i$ produces only one type of good $j \in[0,1]$ with productivity $z_{i}(j)$. The country $i$ 's productivity is a realization of a random variable (drawn independently for each $j$ ) from its specific Fréchet probability distribution $F_{i}(j)=\exp ^{-T_{i} z^{-\theta}}$, where $\theta>1$ and $T_{i}>0$.

The country state of technology parameter $T_{i}$ reflects country $i$ 's absolute advantage. $T_{i}$ governs the location of the distribution: a bigger $T_{i}$ indicates that a higher efficiency draw for any good $j$ is more likely. The parameter $\theta$ governs comparative advantage and it is common across countries: a lower value of $\theta$, generating more heterogeneity across goods, means that comparative advantage exerts a stronger force for trade against the resistance imposed by the geographic barriers $d_{n i}$.

EK treated the cost of a bundle of inputs as the same across commodities within a country. They denote input cost in country $i$ as $c_{i}$, which is defined as follows:

$$
c_{i}=w_{i}^{\beta} p_{i}^{1-\beta},
$$

Since it's a Cobb-Douglas-type cost function $\beta$ stands for the constant labor share; $w_{i}$ is wage in country $i$, while $p_{i}$ is the overall price index of intermediates in country $i$. Having drawn a particular productivity level, the cost of producing a unit of good $j$ in country $i$ is then $\frac{c_{i}}{z_{i}(j)}$. 
The Samuelson iceberg assumption implies that shipping the good from country $i$ to country $n$ requires a per-unit iceberg trade cost of $d_{n i}>1$ for $n \neq i$, with $d_{i i}=1$. It is assumed that cross-border arbitrage forces effective geographic barriers to obey the triangle inequality: for any three countries $i, k$, and $n, d_{n i} \leq d_{n k} d_{k i}$. With the assumption of perfect competition and triangle inequality, the price of a good imported from country $i$ into country $n$ is the unit production cost multiplied by the geographic barriers:

$$
p_{n i}(j)=\left(\frac{w_{i}^{\beta} p_{i}^{1-\beta}}{z_{i}(j)}\right) d_{n i}
$$

Since the Ricardian assumptions imply that country $i$ will search for the better deal around the world (pricing rule), the price of $\operatorname{good} j$ will be $p_{n}(j)=$ $\min \left[p_{n i}(j) ; i=1, \ldots, N\right]$ i.e. the lowest across all countries $i$.

The pricing rule and the productivity distribution give the price index for every destination $n$ :

$$
p_{n}=\gamma \Phi_{n}^{-\frac{1}{\theta}}
$$

where $\Phi_{n}=\sum_{n=1}^{N} T_{i}\left(c_{i} d_{n i}\right)^{-\theta}$ and $\gamma=\left[\Gamma\left(\frac{1+\theta-\sigma}{\theta}\right)\right]^{\frac{1}{1-\sigma}}$. $\Gamma$ is the Gamma function and parameters are restricted such that $\theta>\sigma-1$.

By exploiting the properties of price distribution the fraction of goods that country $n$ buys from country $i$ is also the fraction of its expenditure on goods from country $i$. As EK pointed out, computing the fraction of income spent on imports from $i, \frac{X_{n i}}{X n}$ can be shown to be equivalent to finding the probability that country $i$ is the low-cost supplier to country $n$ given the joint distribution of efficiency levels, prices, and trade costs for any good $j$. The expression for the share of expenditures that $n$ spends on goods from $i$, or the trade share, is

$$
\pi_{n i}=\frac{X_{n i}}{X_{n}}=T_{i}\left(\frac{\left(d_{n i} c_{i}\right)^{-\theta}}{\Phi_{n}}\right)=T_{i}\left(\frac{d_{n i} w_{i}^{\beta} p_{i}^{1-\beta} \gamma}{p_{n}}\right)^{-\theta}
$$

The trade share can be simplified to $\ln \pi_{n i}=S_{i}+S_{n}-\theta \ln \gamma-\theta \ln d_{n i}$, where $S_{i}$ stands for the competitiveness of country $i$, which is function of technology, wages and prices. Mathematically: $S_{i}=\ln T_{i}-\beta \theta \ln w_{i}-\theta(1-\beta) \ln p_{i}$. 
As stated in EK, equation (4) is like a standard gravity equation which relates bilateral trade volumes to characteristics of trade partners and the geography between them.

However, instead of directly estimating this general gravity specification, EK provide a different version of trade equation where a transformed bilateral trade variable is regressed on technology and wages: they manipulate and substitute until the price of intermediates $p_{i}$ disappears: ${ }^{2}$

$$
\ln \left[\frac{X_{n i}^{\prime}}{X_{n n}^{\prime}}\right]=\ln \left[\frac{X_{n i}}{X_{n n}}\right]+\left(\frac{1-\beta}{\beta}\right) \ln \left[\left(\frac{\frac{X_{n}}{X_{n n}}}{\frac{X_{i}}{X_{i i}}}\right)\right]=S_{i}^{\prime}-S_{n}^{\prime}-\theta \ln d_{n i}
$$

where the competitiveness of country $i$ reduces to $S_{i}^{\prime}=\frac{1}{\beta} \ln T_{i}-\theta \ln w_{i}$

As can be observed, country $i$ 's competitiveness is no longer a function of price of intermediaries as it was in the trade share expression. In addition, the wage coefficient gives exactly a measure of the elasticity of trade $\mu_{w}=\mu_{t}=-\theta$. In the trade share equation the wage elasticity is $\mu_{w}=-\beta \theta$ whereas the trade elasticity is $\mu_{t}=-\theta$. Thus, by calculating $\beta$ the effect of wage variation on estimated exporter fixed effects gives an alternative source of identification for the same key parameter. Since for the whole sample $\beta=0.2$, the trade elasticity will be 5 times the estimated wage coefficient.

\section{Definitions, data and econometric specifications}

\subsection{Definitions}

I construct trade shares $\pi_{n i}=X_{n i} / X_{n}$ following EK, Waugh (2010) and Simonovska and Waugh (2011). In the numerator is the aggregate value of manufactured goods that country $i$ imports from country $n$ in thousands of dollars. In the denominator is gross manufacturing production minus total manufactured exports (for the whole world) plus manufactured imports (for only the sample).

To construct home shares $\pi_{n n}=X_{n n} / X_{n}$ I followed the direct measure of the home

\footnotetext{
${ }^{2}$ All the steps that lead to equation 5 , are outlined in Appendix A.1
} 
share employed in Eaton and Kortum (2012) $3^{3}$ Country $n$ 's imports from home $X_{n n}$ are gross manufacturing production less gross manufacturing exports, while its total manufacturing expenditures $X_{n}$ are gross manufacturing production less gross manufacturing exports, plus imports from the other countries of the sample. The home share is equivalent to $1-\sum_{k \neq n}^{N} X_{n i} / X_{n}$, which is the expression commonly found in the literature ${ }^{4}$

The EK's transformed version of bilateral trade in equation (5) differs significantly from the trade share expression. The EK dependent variable equals the normalized trade share by the importer home sales, plus the inverse of home trade share of country $n$, minus the inverse of home trade share of country $i$. While trade share depends negatively on country $n$ 's imports, the EK's transformed version of bilateral trade is a positive function of the ratio between country $n$ and country $i$ 's imports: by keeping $i$ 's imports fixed, higher country $n$ 's imports have positive effect on the EK dependent variable. These different forms of bilateral trade which appear as dependent variable in the two econometric specifications will ultimately lead to different rankings of country's competitiveness $S_{i}$ and $S_{i}^{\prime}$.

The $\beta$ parameter stands for the average labor share in gross manufacturing production in the sample and is calculated as follows:

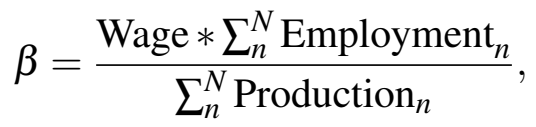

where Wage is the average annual manufacturing salary per employee in the sample, while Employment ${ }_{n}$ is annual manufacturing employment in country $n$. The results are $0.21,0,20$ and 0.20 for the $\mathrm{EK}$, the intermediate and the whole sample, respectively. All these values are in line with EK results. ${ }^{5}$ In order to test whether the measure of $\beta$ is reproduced within the EK model by $\hat{\beta}$, manufacturing prices of intermediaries are regressed on manufacturing wages corrected for worker quality $]^{6}$ From the EK model (equation (2) in Section 2),

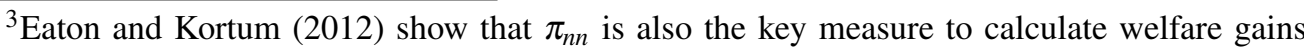
from trade along with trade elasticity $\theta$, labor share $\beta$ and the share of manufactures in the final spending $\alpha$. All these measures with the exception of $\theta$ are directly observable from the data.

${ }^{4}$ See for instance Waugh (2010) or Simonovska and Waugh (2011)

5 Eaton and Kortum (2002) and Eaton and Kortum (2012) obtained respectively 0.21 from a sample of 19 OECD countries, and 0.3 from a larger sample of 31 OECD countries.

${ }^{6}$ This simple regression is based on the intermediate sample of 25 OECD countries; this sample doesn't include New Zealand and Norway because of price data availability.
} 
the price of a unit of good $j$ produced and purchased in country $i$ reduces to: $\ln p_{i i}(j)=-\ln z_{i}(j)+\beta \ln w_{i}+(1-\beta) \ln \bar{p}_{i}$, given that $d_{i i}=1$. By dropping the price index and including technology into the error term, the effect of wages on prices $\hat{\beta}$ is 0.21 (se 0.02 ), a result very close to the true $\beta .7$

To calculate welfare gains from trade following Eaton and Kortum (2012) an additional parameter is needed. The manufacturing share of final spending $\alpha$ is derived directly from the data. This parameter is calculated by solving for $\alpha$ according to the following expression from EK:

$$
X_{n n}+I M P_{n}=(1-\beta)\left(X_{n n}+E X P_{n}\right)+\alpha_{n} Y_{n}
$$

where $I M P_{n}$ is total imports of country $n$ in manufacturing, $E X P_{n}$ stands for total exports of country $n$ in manufacturing while $Y_{n}$ is GDP of country $n$. The values of $\alpha_{n}$ for both samples are in line with the average manufacturing share calculated in EK. For the whole sample the mean of the manufacturing share is 0.12 , while the correspondent value for the EK sample decreases to 0.10 .

\subsection{Data}

My analysis uses data for manufacturing in 1997 for 27 OECD countries 8

Trade data and proxies for geographic barriers. Data on manufacturing production, total manufacturing exports and manufacturing imports are from the latest version of STAN database (2011).9 ${ }^{9}$ Since production and total exports in manufacturing are expressed in national currency they have been converted in current US dollars by using 1997 exchange rates (euro converted historical data for US dollars) from OECD database. Data on weighted distance and all the geographic

\footnotetext{
${ }^{7}$ The price index of country $i$ here is indicated by $\bar{p}_{i}$ instead of simply $p_{i}$. The purpose is to make clear the distinction between the price index and $p_{n i}(j)$.

${ }^{8}$ The limit on the number of countries arises from the availability of data. 1997 has been chosen because GGDC data on relative manufacturing producer prices are available only for this year. Costinot et al. (2012) use the GGDC database as well and they chose 1997 as the base year for exactly the same reason.

${ }^{9}$ For Australia I use estimates published on the previous version of STAN (2005). These estimates are based on ISIC Rev.3 official business survey/census statistics from OECD (SBS) Structural Statistics for Industry and Services database.
} 
barriers used in this paper namely common border, common language and RTA are from CEPII gravity database 10

Determinants of competitiveness. As in EK annual compensation in total manufacturing in national currency are from STAN database. Compensation of employees LABR encompasses wages and salaries of employees paid by producers as well as supplements such as contributions to social security, private pensions, health insurance, life insurance and similar schemes. Compensation of employees are then translated into US current dollars by using OECD exchange rates; in order to obtain the annual compensation per worker, annual compensation is divided by the number of employees in total manufacturing EMPE. Number of employees in total manufacturing are from STAN for large part of my sample; for Australia, Belgium, Czech Republic, Estonia, Greece, Hungary, Ireland, Korea, Poland, Portugal, Slovakia, Slovenia and Sweden I use UNIDO data from the recent INDSTAT2 2012 database. In both INDSTAT2 and STAN databases data are collected using the 2-digit level ISIC Revision 3 industry classification. Compensation per worker data are then adjusted by worker quality, setting $\mathrm{w}_{i}=\left(\mathrm{comp}_{i}\right) \exp ^{-g H_{i}}$, where $h$ is average years of total schooling of population 15 and over in 1992 and $g$ is the return to education. As in EK $g$ is initially set to 0.06 , which Bils and Klenow (2000) suggested as a conservative estimate. In order to test the impact on trade elasticity of a less conservative measure of return to education, wages and total employment will also be corrected using $g=0.12$.

The trade share equation includes manufacturing relative prices for intermediates; data on manufacturing (total manufacturing, excluding electrical) producer relative prices (PPP, in local currency per US dollars) for intermediates are from GGDC productivity database; see Inklaar and Timmer (2008) for details. The manufacturing category here is again defined according to ISIC revision 3 industry classification. The PPP indicates the relative price in a country relative to the US: once converted, a PPP higher than 1 indicates a higher price in that country compared to US. I converted the PPPs in current US dollars by using 1997 exchange rates (euro converted historical data for US dollars) from OECD database.

\footnotetext{
${ }^{10}$ Weighted distance calculates the distance between two countries based on bilateral distances between the biggest cities of those two countries: those inter-city distances are weighted by the share of the city in the overall countrys population. The CEPII gravity database includes data on distance between $n$ and $i$ based on the following formula from Head and Mayer (2002): $\mathrm{d}_{n i}=$ $\left(\sum_{k \in n} \frac{\operatorname{pop}_{k}}{\operatorname{pop}_{n}}\right) *\left(\sum_{l \in i} \frac{\operatorname{pop}_{l}}{\operatorname{pop}_{i}}\right) * \mathrm{~d}_{k l}$, where $\operatorname{pop}_{k}$ stands for the population of agglomeration $k$ belonging to country $n$ while pop $p_{l}$ is the population of agglomeration $l$ belonging to country $i$.
} 
The exceptions are Slovakia and Estonia: these two countries adopted Euro in 2009 and 2011, while Inklaar and Timmer (2008) work has been published earlier in 2008. Thus, for Slovakia and Estonia local currency units for US dollars exchange rates from World Bank have been used.

Following Inklaar and Timmer (2008) the PPP for intermediates for country $i$ is given by:

$\mathrm{PPP}_{\mathrm{II}}=\frac{\mathrm{PPP}_{\mathrm{i}}^{\mathrm{II}}}{\mathrm{PPP}_{\mathrm{US}}^{I I}}$, where II is the sum of sectoral energy, material and services inputs at current prices i.e. II $=$ IIE + IIM + IIS

Total labour force and the inverse of population density are the instruments for wage costs. The inverse of population density is obtained as the inverse of the ratio of country's total labour force over land area. Total labour force data in thousands of workers are obtained from the annual labor force statistics OECD database, with the exception of Estonia, which is from the UN database. Like wages, total employment is corrected for education, setting $\mathrm{L}_{i}=\left(\right.$ work $\left._{i}\right) \exp ^{g H_{i}}$.

Average years of schooling and R\&D expenditures in current US dollars are the proxies for technology. Average years of schooling of adults (aged 15+) for 1992 are obtained through the linear interpolation of Barro and Lee (2010) data. Since Barro Lee data are available 5 years in 5 years, I linearly interpolated 1990 and 1995 in order to get 1992 estimates. All country's R\&D shares of GDP are from the CANA database, a panel dataset for cross-country analyses of national systems 11 the only exception is Korea which is from World Bank because not available in CANA. GDP data in billions of current US dollars are from IMF 12

1990's EK model replication. Appendix A.2 replicates the EK empirical analysis for 1990. This exercise is useful mainly for two reasons. First, since EK used different data sources for instrumental variables, geographic barriers and technology, it's relevant to check whether my data lead to estimates which are consistent with EK results. Second, I show that using a different dataset for average years of education has a quite significant impact on the measure of trade elasticity. For this analysis manufacturing exports, production, wages and employment for 1990 are from the latest version of STAN(2011), while manufacturing bilateral trade data are from an older version of STAN(2002). Geographic variables comes again from

\footnotetext{
${ }^{11}$ Available at http://english.nupi.no/Activities/Projects/CANA

${ }^{12}$ Available at http://www.imf.org/external/data.htm
} 
CEPII gravity database. Data for 1985 education are from Barro and Lee (2010) and Cohen and Soto (2001), whereas 1990 data on R\&D expenditures and GDP are from the same sources used for the 1997 analysis. Cohen and Soto (2001) estimates for 1985 are obtained through linear interpolation 13

\subsection{Econometric specifications}

EK specification. In the first stage a transformed version of bilateral trade is regressed on measures of bilateral trade costs (geographic barriers), importer and exporter fixed effects. The estimated exporter fixed effects obtained in the first stage are then regressed on two proxies for technology (R\&D expenditures and human capital) and wages corrected for worker quality. ${ }^{14}$

From equation (5), the first stage regression becomes:

$\ln \left[\frac{X_{n i}^{\prime}}{X_{n n}^{\prime}}\right]=S_{i}{ }^{\prime}-S_{n}{ }^{\prime}-\theta \mathrm{d}_{n i}-\theta \operatorname{lang}_{n i}-\theta \operatorname{contig}_{n i}-\theta \mathrm{RTA}_{n i}+\theta \delta_{n i}$

Where for every $i \neq n, \ln \overline{\mathrm{d}}_{n i}=\theta \mathrm{d}_{n i}-\theta \operatorname{lang}_{n i}-\theta$ contig $_{n i}-\theta \mathrm{RTA}_{n i}+\theta \delta_{n i}{ }^{15} S_{i}{ }^{\prime}$ and $S_{n}{ }^{\prime}$ are respectively the exporter and importer country fixed effects; $\mathrm{d}_{n i}$ is the weighted distance between country $i$ and country $j$; lang la $_{n i}$ is the effect of importer and exporter sharing a language, while contig ${ }_{n i}$ is the effect of $i$ and $n$ sharing a border. $\mathrm{RTA}_{n i}$ is a common free trade area effect and $\delta_{n i}$ is the residual effect on trade which is assumed orthogonal to all regressors.

In order to capture potential reciprocity in geographic barriers, the error term is assumed to be consisting of two components as in EK, where $\delta_{n i}=\left(\delta_{n i}^{1}+\delta_{n i}^{2}\right)$. The first term is country specific and it affects trade one-way, while the second term is country pair specific and affects trade two-way.

\footnotetext{
${ }^{13}$ Cohen-Soto database is available at http://soto.iae-csic.org/Data.htm

${ }^{14}$ Many of the gravity based $\theta$ coefficients in the literature identified by Head and Mayer (2013) have been estimated through a one-step procedure. Appendix A.3 provides the correspondent onestep estimation of the EK competitiveness equation for 1997 as well as the theoretical explanations of why the two-step procedure should be preferred.

${ }^{15}$ In Section 2 I indicate geographic barriers as $\mathrm{d}_{n i}$; here I used $\overline{\mathrm{d}}_{n i}$ to clarify the distinction between weighted distance $\mathrm{d}_{n i}$ and the parameter which includes distance along with all the geographic dummies $\overline{\mathrm{d}}_{n i}$.
} 
Santos Silva and Tenreyro (2006) argue that OLS with log of trade as dependent variable becomes an inconsistent estimator in the presence of Poisson-type heteroskedasticity ${ }_{16}$ Santos Silva and Tenreyro (2006) suggested Poisson pseudoMLE as a valid alternative to linear-in-logs OLS for multiplicative models like the gravity equation. The Poisson PML (PPML) estimator guarantees consistent estimates regardless of the distribution of the error term, as long as:

$$
E\left[X_{n i} \mid z_{n i}\right]=\exp \left(z_{n i}^{\prime} v\right)
$$

where $X_{n i}$ is bilateral trade, $z_{n i}^{\prime}$ is the transpose of a vector of the trade cost variables and $v$ is the correspondent vector of coefficients.

The Poisson PML estimator has often been used for count data models. Santos Silva and Tenreyro (2006) estimated a gravity model with Poisson PML using bilateral trade flows measured in levels as dependent variable. However, as proved by Gourieroux et al. (1984), the PML method with Poisson family may be applied even if the dependent variable is any real number: as long as the trade flow is greater or equal than zero, the estimator based on the Poisson likelihood function is consistent. Since the trade share $X_{n i} / X_{n}$ is strictly positive because $X_{n i}>0$ and the transformed version of bilateral trade $X_{n i}^{\prime} / X_{n n}^{\prime}$ is always greater than zero for both samples, both specifications have the requisites to be estimated consistently with Poisson PML.

After conducting a Monte Carlo simulation, Head and Mayer (2013) argue that Poisson PML should not replace OLS as the workhorse for gravity equation; alternatively, they suggest to use Poisson PML as part of a robustness-exploring ensemble which includes OLS and Gamma PML 17 Following Head and Mayer (2013) I test the reliability of the first-stage OLS estimates by contrasting OLS with Poisson PML results. As noted by Head and Mayer (2013), if there's a significant discrepancy between Poisson and OLS coefficients, then it is reasonable

\footnotetext{
${ }^{16}$ Since bilateral trade flows are all positive in my samples, the lack of zeros would pose no problem for the use of a gravity equation in log linear form.

${ }^{17}$ In a second simulation Head and Mayer (2013) reveal that Gamma PML does not perform well in the presence of constant variance to mean ratio (CVMR) error term and is even biased under the log-normal assumption. They conclude that the performance of this estimator worsens probably because of the presence of zeros. However, as opposed to Gamma PML, Poisson PML with country fixed effects is showed to be unbiased with CVMR errors in both Head and Mayer (2013) simulations; given these results, the following empirical analysis uses PPML as the only estimator whose performance is compared to OLS.
} 
to conclude that heteroskedasticity is an issue and the OLS estimates are unreliable. In Anderson and Yotov (2010a), Helpman et al. (2008) and Santos Silva and Tenreyro (2006) the comparison between the Poisson PML and the OLS gravity estimates reveal that the latter are biased upward.

In the gravity literature importer and exporter fixed effects have mainly been seen as vital controls needed to obtain consistent estimates of the trade cost variables but not particularly useful in their own right. Santos Silva and Tenreyro (2006), Head and Mayer (2013) and Eaton et al. (2012) contrast OLS with PPML coefficients by comparing a few key gravity variables like distance, RTA and the usual geographic dummies without showing the effects of heteroskedasticity-type-ofbias on importer and exporter fixed effects. Given the importance of these coefficients for the estimation of trade cost elasticity through the EK two-step competitiveness equation methodology, the comparison between OLS and Poisson PML estimates will be extended also to exporter fixed effects.

From equation (5) the second stage regression becomes:

$$
\hat{S}_{i}^{\prime}=\alpha_{0}+\alpha_{R} \ln \mathrm{R} \& \mathrm{D}_{i}+\alpha_{H} \ln \mathrm{H}_{i}-\theta \ln \mathrm{w}_{i}+u_{i}
$$

where $\mathrm{R} \& \mathrm{D}_{i}$ is country $i$ 's $\mathrm{R} \& \mathrm{D}$ expenditure, $\mathrm{H}_{i}$ is the average years of education, $\mathrm{w}_{i}$ is country $i$ wages adjusted for education and $u_{i}$ is the error term assumed orthogonal to all regressors. In this specification the elasticity of trade $\theta$ coincides with the effect of wages on competitiveness.

Trade share specification. From equation (4) I obtain the following specification:

$$
\ln \left(\frac{X_{n i}}{X_{n}}\right)=S_{i}+S_{n}-\theta \ln d_{n i}-\theta \operatorname{lang}_{n i}-\theta \operatorname{contig}_{n i}-\theta \mathrm{RTA}_{n i}+\theta \varphi_{n i}
$$

where $\theta \ln \gamma$ is included into the error term $\varphi_{n i}$, which is orthogonal to all regressors. The trade share second stage specification becomes $\hat{S}_{i}=\alpha_{0}+\alpha_{R} \ln \mathrm{R}_{2} \mathrm{D}_{i}+$ $\alpha_{H} \ln \mathrm{H}_{i}-\theta \beta \ln \mathrm{w}_{i}-\theta(1-\beta) \ln \mathrm{p}_{i}+u_{i}$.

To better compare the trade share results with the estimates from the EK model, in the trade share regressions $\beta$ is substituted with the actual value of the labour share for each sample. This allows to easily confront the trade elasticity coefficients between these two different specifications, since we are back to $\mu_{t}=-\theta$ as in the EK original competitiveness equation. For the whole sample, the second stage 
regression reduces to $\hat{S}_{i}=\alpha_{0}+\alpha_{R} \ln R \& \mathrm{D}_{i}+\alpha_{H} \ln \mathrm{H}_{i}-\theta 0.2 \ln \mathrm{w}_{i}-\theta 0.8 \ln \mathrm{p}_{i}+$ $u_{i}{ }^{18}$

Since data on manufacturing relative prices are not available for Norway and New Zealand, the trade share regression is estimated initially only for an intermediate sample of 25 OECD countries. Once the relative price variable is dropped because proved to be redundant, the trade share is estimated for the other two samples as well. Poisson PML is used as a robustness check for the OLS estimations in the first stage, and the resulting exporter fixed effects are utilized as dependent variables in the second stage 19

\section{Results}

\subsection{EK competitiveness equation}

The EK empirical analysis for 1990 is replicated in Appendix A.2. The results are reassuring, since the resulting measure of trade cost elasticity is very close to the EK benchmark of 3.60. By using the same sources, the next step is repeating the same exercise for 1997, by checking first for the presence of heteroskedasticitytype-of-bias in the OLS estimates.

Following Santos Silva and Tenreyro (2006) the first stage has been estimated using both OLS and Poisson PML. The results are reported in Table 4. As opposed to the $1990 \mathrm{EK}$ analysis, in the 1997 specification the RTA effect is captured by a common bloc dummy. For both samples, there's a significant discrepancy between OLS and Poisson PML estimates, which indicates a bias in the OLS results due to heteroskedasticity. The direction of the bias is not as clear as in Anderson and Yotov (2010a), Helpman et al. (2008) and Santos Silva and Tenreyro (2006), where there's a tendency for OLS coefficients to be biased upward. The discrepancy between OLS and PPML results showed in Table 4 is particularly evident by looking at the $\hat{S}_{i}^{\prime}$ coefficients. In line with Anderson and Yotov (2010b) there's

\footnotetext{
${ }^{18} \beta$ takes the value of 0.21 in the EK sample.

${ }^{19}$ Applying the Stata Poisson command to a gravity model which includes the trade share $\pi_{n i}$ as dependent variable and country specific fixed effects, provides the Multinomial PML estimator as proved by Sebastian Sotelo in unpublished notes. Eaton et al. (2012) argue that Multinomial PML is the best estimator in models with a finite number of buyers and sellers, where the EK continuum assumption is abandoned.
} 
almost perfect correlation between OLS and PPML $\hat{S}_{i}{ }^{\prime}$ results: for both samples the correlation coefficient is 0.99 . However, since the first stage bias affects both mean and variance of country's competitiveness, OLS and PPML $\hat{S}_{i}^{\prime}$ coefficients cannot be used interchangeably as second stage dependent variable. Therefore, despite the high correlation between OLS and PPML, the heteroskedasticity-typeof-bias in the OLS first stage coefficients leads to biased estimates of $\theta$. This is confirmed by the results showed in Table 1 .

Table 1 reports the second stage results for 1997. The estimates are obtained using 2SLS. As Head and Mayer (2013) pointed out, wages are likely to be simultaneously determined with trade patterns; thus, in order to correct for endogeneity I instrument for wages using 2SLS. The instruments are the same as in EK: total labor force and the inverse of population density which proxy respectively for labour supply and for productivity outside manufacturing. As in Costinot et al. (2012), EK and Erkel-Rousse and Mirza (2002), the estimated effect of the proxy for exporter competitiveness is larger when instrumenting using OLS: trade elasticity increases from 5.09 (se 3.02) to 6.32 (se 3.39) for the EK sample, while $\theta$ goes from 1.34 (se 1.07) to 2.01 (se 1.58) for the whole sample. This trend applies also when the second stage dependent variable is estimated with PPML: $\theta$ increases from 4.00 (se 3.18) to 4.99 (se 3.46) for the EK sample, while the same parameter goes from 1.37 (se 1.17) to 2.50 (se 1.65) for the whole sample.

The evidence indicates a sort of instability of the measure of trade elasticity: this coefficient varies dramatically with sample size and over time. By considering the same EK sample, the difference between the 1997 estimate of $\theta$ and the correspondent measure for 1990 is around 2.92. In addition, the discrepancy between the same parameter estimated using the two different samples for 1997 is 4.32: the magnitude of $\theta$ decreases as the sample size increases. This huge variability is in line with the findings of Head and Mayer (2013).20 Finally, as expected, the discrepancy between OLS and PPML first stage coefficients significantly affects the resulting measure of $\theta$ : the difference between PPML and OLS wage elasticities is around 1.30 for the EK sample and 0.50 for the whole sample.

According to the recent estimates of Barro and Lee (2010), less advanced economies show low returns to education, whereas an additional year of schooling in ad-

\footnotetext{
${ }^{20}$ Head and Mayer (2013) identified in the literature 744 trade elasticity coefficients obtained for the full sample of 32 papers: they show that the mean of the estimates of $\theta$ obtained dealing with the multilateral resistance terms through country fixed effects is 4.12 , but the standard deviation is twice as large.
} 
Table 1: Second stage - Competitiveness equation

\begin{tabular}{l|cccc|cccc}
\hline \hline & OLS & 2SLS & OLS(p) & 2SLS(p) & OLS & 2SLS & OLS(p) & 2SLS(p) \\
\hline lnWages $_{i}$ & -5.09 & $-6.32^{*}$ & -4.00 & -4.99 & -1.34 & -2.01 & -1.37 & -2.50 \\
& $(3.02)$ & $(3.39)$ & $(3.18)$ & $(3.46)$ & $(1.07)$ & $(1.58)$ & $(1.17)$ & $(1.65)$ \\
& & & & & & & & \\
$\operatorname{lnR} \& \mathrm{D}_{i}$ & $1.67^{* * *}$ & $1.78^{* * *}$ & $1.61^{* * *}$ & $1.71^{* * *}$ & $1.66^{* * *}$ & $1.85^{* * *}$ & $1.61^{* * *}$ & $1.93^{* * *}$ \\
& $(0.41)$ & $(0.40)$ & $(0.42)$ & $(0.40)$ & $(0.33)$ & $(0.38)$ & $(0.38)$ & $(0.41)$ \\
$1 / \mathrm{H}_{i}$ & & & & & & & & \\
& 14.80 & 14.01 & 21.79 & 14.04 & 24.37 & 28.37 & 17.42 & 24.27 \\
& $(19.33)$ & $(21.50)$ & $(14.68)$ & $(23.35)$ & $(21.08)$ & $(24.30)$ & $(23.45)$ & $(28.01)$ \\
Constant & 45.25 & 57.22 & 34.62 & $44.31^{*}$ & 8.12 & 13.73 & 9.18 & 18.77 \\
& $(27.86)$ & $(31.20)$ & $(29.41)$ & $(31.81)$ & $(8.30)$ & $(12.68)$ & $(9.09)$ & $(13.08)$ \\
\hline Observations & 19 & 19 & 19 & 19 & 27 & 27 & 27 & 27 \\
$\mathrm{R}^{2}$ & 0.58 & 0.57 & 0.55 & 0.55 & 0.61 & 0.61 & 0.55 & 0.52 \\
Root MSE & 2.09 & 2.11 & 2.15 & 2.17 & 2.26 & 2.28 & 2.46 & 2.53 \\
\hline \hline
\end{tabular}

vanced countries has an impact on output of $0.13{ }^{21}$ Since the empirical analysis is based on samples of OECD countries, it's interesting to test the impact on trade elasticity of a less conservative measure of $g$. As it turned out, doubling the measure of the return to education has a quite significant impact on the wage effect only for the EK sample. Correcting wages and total labour force with $g=0.12$ instead of $g=0.06$, reduces the measure of $\theta$ by 0.63 , and 0.05 for the EK and the whole sample, respectively ${ }^{22}$

Before proceeding to the trade share regression analysis, two important remarks about Table 1 results are worth mentioning.

- The sign of human capital is the opposite of what the theory predicts. EK obtained the correct sign for education, but the resulting effect was not statistically significant 23

\footnotetext{
${ }^{21}$ Barro-Lee estimates of rates of return to education significantly vary across regions. The estimates are the highest at $13.3 \%$ for the group of advanced countries. In contrast, the returns are around 6.5\% in less advanced areas such as Sub-Saharan Africa and Latin America.

${ }^{22}$ These numbers refer to the 2 SLS from OLS first stage estimations. The correspondent measures from Poisson PMLE are 0.51 and 0.06.

${ }^{23}$ In EK the effect of (the inverse of) education on country i's competitiveness is -22.7 (se 21.3).
} 
- The standard errors of the competitiveness regression coefficients are relatively high (with the exception of R\&D); this leads to three 2SLS $\theta$ coefficients statistically insignificant.

\subsection{Trade share regression}

In order to estimate the trade share regression a smaller sample of 25 countries has been used, since data on manufacturing relative prices are not available for Norway and New Zealand. Table 2 reports the two-step 2SLS coefficients. ${ }^{24}$ The dependent variable is exporter fixed effects $\hat{S}_{i}$ obtained from a first stage regression estimated using both OLS and Poisson PML. The results indicate that wages and $R \& D$ are the only statistically significant coefficients among the determinants of competitiveness. By using the same instruments for wages, the dependent variable obtained from Poisson PML leads to a measure of trade cost elasticity of 3.91. The correspondent two-step measure of $\theta$ from OLS is 2.89 and it's not statistically significant.

However, the coefficients of the exporter relative price on competitiveness have the wrong sign and both the effects are not statistically significant. This is not surprising, since most of the impact of $p_{i}$ is likely to be captured by the wage parameter, which makes the price variable redundant. By running the same regression without controlling for prices the two-step measure of $\theta$ obtained from the OLS first stage is 2.58 , statistically significant at $5 \%$ level, whereas the correspondent parameter from the Poisson PML first stage is 3.55 , statistically significant at $1 \%$.

Since the price variable is proved to be redundant in this model, it's now possible to compare the trade share estimations of $\theta$ with the measures of trade elasticity obtained previously from the EK benchmark model, for both the EK and the whole sample.

Table 5 reports the first-stage regression results of the trade share specification. As in the EK's first stage, I check for the presence of heteroskedasticity-type-of-bias in the OLS estimates by comparing OLS with Poisson PML. The results indicate the presence of an upward bias of the OLS coefficients, particularly evident in

\footnotetext{
${ }^{24}$ The first stage is estimated using OLS with robust standard errors and Poisson PML. The estimates are available upon request.
} 
Table 2: Trade share 2SLS - 25 countries

\begin{tabular}{|c|c|c|c|c|}
\hline & $2 \mathrm{SLS}(\mathrm{p})$ & $2 \mathrm{SLS}(\mathrm{p})$ & 2 SLS & 2 SLS \\
\hline$\overline{\text { lnWages }}_{i}$ & $\begin{array}{l}-3.91^{*} \\
(1.99)\end{array}$ & $\begin{array}{c}-3.55^{* * *} \\
(1.09)\end{array}$ & $\begin{array}{c}-2.89 \\
(2.10)\end{array}$ & $\begin{array}{c}-2.58^{* *} \\
(1.22)\end{array}$ \\
\hline $\operatorname{lnR} \& \mathrm{D}_{i}$ & $\begin{array}{c}0.89^{* * *} \\
(0.08)\end{array}$ & $\begin{array}{c}0.91^{* * *} \\
(0.07)\end{array}$ & $\begin{array}{c}0.94^{* * *} \\
(0.08)\end{array}$ & $\begin{array}{c}0.99^{* * *} \\
(0.07)\end{array}$ \\
\hline $1 / \mathrm{H}_{i}$ & $\begin{array}{c}7.47 \\
(5.19)\end{array}$ & $\begin{array}{c}7.85 \\
(5.76)\end{array}$ & $\begin{array}{c}3.46 \\
(5.80)\end{array}$ & $\begin{array}{c}4.47 \\
(6.51)\end{array}$ \\
\hline $\operatorname{lnPrice}_{i}$ & $\begin{array}{c}0.86 \\
(1.62)\end{array}$ & & $\begin{array}{c}1.29 \\
(1.58)\end{array}$ & \\
\hline Constant & $\begin{array}{c}5.43 \\
(3.91)\end{array}$ & $\begin{array}{l}4.69^{* *} \\
(1.73)\end{array}$ & $\begin{array}{c}3.87 \\
(3.98)\end{array}$ & $\begin{array}{c}3.12 \\
(1.87)\end{array}$ \\
\hline Observations & 25 & 25 & 25 & 25 \\
\hline $\mathrm{R}^{2}$ & 0.93 & 0.93 & 0.94 & 0.93 \\
\hline Root MSE & 0.45 & 0.44 & 0.50 & 0.50 \\
\hline
\end{tabular}

Notes: White robust standard errors in parentheses.

Notes: in columns 1 and 2 dependent variable obtained with PPML.

${ }^{*} p<0.05,{ }^{* *} p<0.01,{ }^{* * *} p<0.001$

the exporter fixed effects $\hat{S}_{i}$. The correlation between OLS and PPML exporter fixed effects coefficients is still very high, around 0.98 for both samples. Again, these highly correlated set of coefficients $\hat{S}_{i}$ which are almost equivalent in relative terms do not provide any information regarding the magnitude of $\theta$ estimated in the second stage.

What emerges from the comparison between $\hat{S}_{i}$ and $\hat{S}_{i}{ }^{\prime}$ is the relatively low level of correlation between the two sets of coefficients across both econometric techniques: the correlation coefficient drops to 0.64 and 0.69 for the EK sample, and to 0.78 and 0.76 for the whole sample ${ }^{25}$ These relatively low levels of correlation between $\hat{S}_{i}$ and $\hat{S}_{i}{ }^{\prime}$ are coupled with significant differences in the variance and the mean between the two set of coefficients for both samples ${ }^{26}$ In addition, the two different specifications lead to different rankings of country's competitiveness: since the two specifications have different forms of bilateral trade as dependent variable, the measure of country's competitiveness varies accordingly. For in-

\footnotetext{
${ }^{25}$ For each sample the first and the second coefficients denote the correlation between OLS and PPML set of coefficients, respectively.

${ }^{26}$ Standard deviation and mean results are available upon request.
} 
stance, by comparing column 1 results between Table 4 and Table 5 , Belgium goes from being the least competitive country in the sample, importing almost two times less than Australia $[\exp (-10.868)-1=0.99]$, to import only $30.7 \%$ less than the same country base $[\exp (-0.368)-1=0.307]$.

Table 3 shows the second stage results of the trade share specification. The table reports the two-step coefficients for the EK and the whole sample. The dependent variables of columns 2 and 4 are obtained using Poisson PML, whereas the $\hat{S}_{i}$ of columns 1 and 3 are from OLS. These results present some interesting features. First, the two measures of trade cost elasticity estimated from the whole sample are very distant from both the EK benchmark of 3.60 and the average of 4.12 reported in Head and Mayer (2013). Second, the impact of heteroskedasticitytype-of-bias is even more significant than in the previous competitiveness equation results: the difference between $\theta$ coefficients obtained with Poisson PML and OLS is around 2.63 for the EK sample and 1.23 for the whole sample. Third, the $\theta$ parameters obtained from a PPML first stage are all statistically significant.

Table 3: Trade share 2SLS - EK and whole sample

\begin{tabular}{|c|c|c|c|c|}
\hline & 2 2SLS & 2SLS(p) & 2 2SLS & $2 \mathrm{SLS}(\mathrm{p})$ \\
\hline lnWages $_{i}$ & $\begin{array}{l}-2.28 \\
(1.89)\end{array}$ & $\begin{array}{c}-4.91^{* * *} \\
(1.50)\end{array}$ & $\begin{array}{l}-0.63 \\
(1.11)\end{array}$ & $\begin{array}{l}-1.86^{*} \\
(0.97)\end{array}$ \\
\hline $\operatorname{lnR} \& \mathrm{D}_{i}$ & $\begin{array}{c}0.85^{\text {*** }} \\
(0.08)\end{array}$ & $\begin{array}{c}0.83^{* * *} \\
(0.04)\end{array}$ & $\begin{array}{c}0.91^{* * *} \\
(0.07)\end{array}$ & $\begin{array}{c}0.82^{* * *} \\
(0.06)\end{array}$ \\
\hline $1 / \mathrm{H}_{i}$ & $\begin{array}{l}-1.71 \\
(5.91)\end{array}$ & $\begin{array}{l}-2.61 \\
(4.00)\end{array}$ & $\begin{array}{c}1.31 \\
(7.99)\end{array}$ & $\begin{array}{c}0.00 \\
(6.87)\end{array}$ \\
\hline Constant & $\begin{array}{c}3.22 \\
(3.76) \\
\end{array}$ & $\begin{array}{c}8.79^{* * *} \\
(3.10)\end{array}$ & $\begin{array}{l}-0.05 \\
(1.57) \\
\end{array}$ & $\begin{array}{l}2.53^{*} \\
(1.44)\end{array}$ \\
\hline Observations & 19 & 19 & 27 & 27 \\
\hline $\mathrm{R}^{2}$ & 0.94 & 0.96 & 0.93 & 0.91 \\
\hline Root MSE & 0.36 & 0.27 & 0.52 & 0.47 \\
\hline
\end{tabular}

For the EK sample the inverse of education has the right sign as in EK. However, for the whole sample the sign is again reverted. One of the possible explanations is that some of the countries that trade less in the enlarged sample are those char- 
acterized by high levels of average years of education, especially former socialist economies such as Estonia, Slovenia, Slovakia, Czech Republic and Hungary.

What emerges from both specifications is the value of $\theta$ which considerably decreases as the sample size expands by including emerging economies. This evidence is contrary to the assumption that $\theta$ is common to all countries: the results suggest that including countries with lower income decreases the magnitude of trade cost elasticity. This finding is fully consistent with the results of Waugh (2010). 27

The trade share estimates of trade cost elasticity can be considered as a sort of additional robustness check for the first stage OLS results. By comparing the results across specifications, the $S_{i}$ estimated with PPML lead to very similar measures of $\theta . S_{i}$ from Poisson PML yield statistically significant measures of $\theta$ of 4.91 and 1.86: these estimates are only 0.08 and 0.64 lower than the correspondent results obtained from the EK benchmark model. On the contrary, $S_{i}$ estimated with OLS leads to statistically insignificant trade elasticity parameters of 2.28 and 0.63: these values are 4.31 and 1.38 lower than the correspondent EK benchmark results of Table 3. These findings confirm that heteroskedasticity-type-of-bias is an issue and therefore the estimation of trade elasticity through the two-step competitiveness equation can be considered reliable if $S_{i}$ are estimated with econometric techniques, such as Poisson PML, which produce consistent results in presence of heteroskedastic error terms.

\section{Welfare analysis}

As Eaton and Kortum (2012) pointed out, anything that lowers a country's cost of serving a market, means more purchases are shifted there. How much depends on $\theta$. Given a change in trade costs, the higher $\theta$, the more similar are the technologies (and costs) across goods for all countries, the bigger the shift in trade shares. Eaton and Kortum (2012) provides a simple framework which allows to interpret and calculate how a shift in trade elasticity traslates into welfare gains

\footnotetext{
${ }^{27} \mathrm{As}$ Waugh (2010) pointed out, one should expect richer countries to have a lower value of $\theta$ because of more variation in productivity and therefore more incentives to trade. The evidence suggests otherwise.
} 
from trade. Following Eaton and Kortum (2012) the gains from trade of country $n$ are expressed as follows:

$$
G_{n}=100 *\left[\pi_{n n}\left(-\alpha_{n} / \theta \beta\right)-1\right]
$$

where $\pi_{n n}$ is the home share of country $n, \alpha_{n}$ is the manufacturing share of country $n$ and $\beta$ is the average labor share calculated for each sample. Eaton and Kortum (2012) argue that $\alpha / \theta \beta$ is the elasticity which translates a smaller home share into larger gains from trade. The benefits from trade are limited to the manufacturing sector, but since manufactures represents a major input into the production of manufactures there are indirect benefits of trade in lowering input costs. These two opposite effects are controlled for by the parameters $\alpha$ and $\beta$ in equation $(8,28$.

As the previous section clearly indicates, the bias in the first stage OLS results due to heteroskedasticity significantly affects the measure of $\theta$. Table 6 shows the implications of this bias in the calculation of the welfare gains from trade. The home share $\pi_{n n}, \beta$ and $\alpha$ are all calculated directly from the data. While Eaton and Kortum (2012) and EK impose a common manufacturing demand share $\alpha$ across countries, the counterfactuals of Table 6 are performed using $\alpha_{n}$. The values of the manufacturing share are calculated according to equation (7) and are reported in the first column of Table 7 .

Column 1 of Table 6 reports the home share for all the 19 countries of the EK sample ${ }^{29}$ Column 2 shows the values of $G_{n}$ by using a biased measure of $\theta=2.28$, whereas column 3 reports the correspondent values of $G_{n}(p)$ obtained utilizing the unbiased estimate of $\theta=4.91$. Lastly, column 4 reports the welfare gains from trade by using the 1990 Eaton and Kortum (2002) benchmark $\theta=3.60$.

In general, gains from trade are substantial, especially for small economies. Countries with a relatively small size such as Belgium, Austria and Portugal show large

\footnotetext{
${ }^{28}$ In Arkolakis et al. (2012) the same expression for the elasticity which translates a smaller home share into larger gains from trade is $1 / \theta$.

${ }^{29}$ Since the trade share measures of $\theta$ from the EK sample are closer in magnitude to the average of 4.12 reported in Head and Mayer (2013) then the correspondent parameters from the whole sample, the values of trade cost elasticity used to calculate welfare gains are taken from the first two columns of Table 3. In addition, the trade share $\theta$ coefficient from PPML is statistically significant at $1 \%$ level. Lastly, the coefficients obtained from the whole sample in general are too low in absolute value compared to the value of 4.12 reported in Head and Mayer (2013).
} 
gains. As expected, the difference in the measure of $\theta$ due to the heteroskedasticitytype-of-bias significantly affects $G_{n}$ : a decrease of 2.63 in the magnitude of trade elasticity produces on average an increase of $122 \%$ in terms of welfare gains. By comparing the $G_{n}(p)$ results of column 3 to the gains $G_{n}(E K)$ obtained using the 1990 EK benchmark $\theta=3.60$ showed in column 4 , a decrease of 1.31 of the same key parameter gives on average an increase of $38 \%$.

Lastly, as it emerges from Table 7, using a common value for manufacturing share has very important implications for welfare analysis. Since $\alpha_{n}$ varies by country, utilizing common values such as the sample mean of the manufacturing share for all countries creates distortions in the calculation of $G_{n}$. Column 2 reports the change in welfare gains from trade between $G_{n}(p)$ and a measure of benefits obtained using a common larger manufacturing share of 0.2 as in Eaton and Kortum (2012) and Dekle et al. (2007). The results indicate that, all else being equal, imposing a larger $\alpha$ for all $n$ tends to significantly overestimate the benefits from trade, especially for those countries with a very small manufacturing share of final spending. In particular, Belgium, Finland and Sweden increase their welfare gains from trade by $463 \%, 550 \%$ and $305 \%$, respectively.

By the same token, using the sample mean $\alpha$ as a common manufacturing share for all countries, penalizes those economies with relatively high $\alpha_{n}$ and overestimates welfare gains for countries with a lower share. As it is reported in column 3, the country with the highest manufacturing share in the sample, Portugal, decreases its benefits from trade by $45 \%$, while Belgium, Finland and Sweden preserve very large gains. On the other hand, the two countries with the lowest manufacturing share in the sample, Belgium and Finland, increase their welfare gains by $153 \%$ and $232 \%$, respectively.

\section{Conclusions}

What emerges from the empirical analysis is the extreme variability of the trade elasticity parameter obtained from both the EK and the trade share competitiveness equations: the $1997 \theta$ coefficients are all quite distant from the 1990 Eaton and Kortum (2002) benchmark of 3.60 and they vary dramatically with the sample size.

As opposed to large part of the gravity literature which sees importer and exporter fixed effects only as vital controls needed to obtain consistent estimates of the 
trade cost variables, this paper provides evidence on the unbiasedness of exporter fixed effects as an essential requisite to obtain reliable estimates of trade cost elasticity through the EK two-step competitiveness equation methodology. The statistics reveal that the estimation of trade cost elasticity can be considered reliable if and only if $S_{i}$ are estimated with econometric techniques, such as Poisson PML, which produce consistent results in presence of heteroskedastic error terms.

Since trade cost elasticity has a key role in the calculation of welfare gains from trade, the resulting extreme variability of $\theta$ poses a problem of identification of these benefits. For instance, by keeping fixed the home shares, a fall of 1.31 in the magnitude of trade elasticity produces on average an increase in terms of welfare of $38 \%$. Similar distortions in the calculation of benefits from trade arise by utilizing a common manufacturing share parameter for all countries. The evidence indicates that using the sample mean of the manufacturing share as a common parameter substantially overestimates welfare gains for countries with a lower share and severely penalizes those economies with a relatively high demand for final manufactures. 
Table 4: EK first stage regression 1997

\begin{tabular}{|c|c|c|c|c|}
\hline $\begin{array}{l}\text { Estimator } \\
\text { Dependent variable }\end{array}$ & $\begin{array}{c}\text { OLS } \\
\ln \left[\frac{\mathrm{X}_{n i}^{\prime}}{\mathrm{X}_{n n}^{\prime}}\right]\end{array}$ & $\begin{array}{c}\text { PPML } \\
{\left[\frac{\mathrm{X}_{n i}^{\prime}}{\mathrm{X}_{n n}^{\prime}}\right]}\end{array}$ & $\begin{array}{c}\text { OLS } \\
\ln \left[\frac{\mathrm{X}_{n i}^{\prime}}{\mathrm{X}_{n n}^{\prime}}\right]\end{array}$ & $\begin{array}{c}\text { PPML } \\
{\left[\frac{\mathrm{X}_{n i}^{\prime}}{\mathrm{X}_{n n}^{\prime}}\right]}\end{array}$ \\
\hline \multicolumn{5}{|l|}{ Variable } \\
\hline Shared border $_{n i}$ & $0.27^{*}$ & -0.13 & $0.35^{* * *}$ & $0.53^{* * *}$ \\
\hline Shared language $_{n i}$ & $0.26^{* *}$ & 0.00 & $0.32^{* * *}$ & $0.14^{*}$ \\
\hline $\mathrm{RTA}_{n i}$ & -0.03 & $-0.90^{* * *}$ & $1.03^{* * *}$ & $0.65^{*}$ \\
\hline $\operatorname{lnDistance}_{n i}$ & $-1.29^{* * *}$ & $-1.48^{* * *}$ & $-0.72^{* * *}$ & $-0.48^{* * *}$ \\
\hline Country & $\hat{S}_{i}^{\prime}$ & $\hat{S}_{i}^{\prime}$ & $\hat{S}_{i}^{\prime}$ & $\hat{S}_{i}^{\prime}$ \\
\hline AUSTRALIA & 0.000 & 0.000 & 0.000 & 0.000 \\
\hline AUSTRIA & -3.166 & -3.492 & -2.645 & -1.991 \\
\hline BELGIUM & -10.868 & -11.295 & -9.726 & -8.794 \\
\hline CANADA & -1.206 & -1.257 & -0.840 & -0.373 \\
\hline CZECH REPUBLIC & -3.264 & -3.351 & & \\
\hline DENMARK & -3.329 & -4.049 & -2.734 & -2.316 \\
\hline ESTONIA & -10.408 & -9.844 & & \\
\hline FINLAND & -1.023 & -0.792 & -0.894 & -0.057 \\
\hline FRANCE & 0.458 & 0.714 & 0.769 & 1.807 \\
\hline GERMANY & 1.207 & 0.766 & 1.599 & 2.145 \\
\hline GREECE & -3.191 & -2.498 & -2.916 & -1.925 \\
\hline HUNGARY & -3.567 & -3.119 & & \\
\hline IRELAND & -3.876 & -3.484 & & \\
\hline ITALY & 1.031 & 0.956 & 1.242 & 2.089 \\
\hline JAPAN & 3.446 & 3.514 & 3.645 & 3.976 \\
\hline KOREA & 1.443 & 0.894 & & \\
\hline NETHERLANDS & -3.756 & -4.338 & -3.011 & -1.769 \\
\hline NEW ZEALAND & -1.222 & -0.390 & -1.148 & -0.515 \\
\hline NORWAY & -2.742 & -3.061 & -2.286 & -1.847 \\
\hline POLAND & -2.351 & -2.103 & & \\
\hline PORTUGAL & -2.221 & -3.087 & -1.907 & -2.347 \\
\hline SLOVAKIA & -5.273 & -4.917 & & \\
\hline SLOVENIA & -5.857 & -6.449 & & \\
\hline SPAIN & -0.121 & 0.095 & 0.016 & 1.017 \\
\hline SWEDEN & -1.093 & -0.570 & -0.646 & 0.607 \\
\hline UNITED KINGDOM & 0.260 & -0.511 & 0.696 & 1.618 \\
\hline UNITED STATES & 3.645 & 3.935 & 3.792 & 4.670 \\
\hline Observations & 702 & 702 & 342 & 342 \\
\hline $\mathrm{R}^{2}$ & 0.98 & & 0.99 & \\
\hline Pseudo $\mathrm{R}^{2}$ & & 0.99 & & 0.93 \\
\hline
\end{tabular}


Table 5: Trade share first stage regression 1997

\begin{tabular}{|c|c|c|c|c|}
\hline $\begin{array}{l}\text { Estimator } \\
\text { Dependent variable }\end{array}$ & $\begin{array}{c}\text { OLS } \\
\ln \left[\frac{X_{n i}}{X_{n}}\right]\end{array}$ & $\begin{array}{c}\text { PPML } \\
{\left[\frac{X_{n i}}{X_{n}}\right]}\end{array}$ & $\begin{array}{c}\text { OLS } \\
\ln \left[\begin{array}{l}\mathrm{X}_{n i} \\
\mathrm{X}_{n}\end{array}\right]\end{array}$ & $\begin{array}{c}\text { PPML } \\
{\left[\begin{array}{c}\mathrm{X}_{n i} \\
\mathrm{X}_{n}\end{array}\right]}\end{array}$ \\
\hline \multicolumn{5}{|l|}{ Variable } \\
\hline Shared border ${ }_{n i}$ & $0.27^{*}$ & $0.22^{* *}$ & $0.35^{* * *}$ & $0.24^{* *}$ \\
\hline Shared language $_{n i}$ & $0.26^{* *}$ & $0.29^{* *}$ & $0.32^{* * *}$ & $0.35^{* * *}$ \\
\hline $\mathrm{RTA}_{n i}$ & -0.03 & -0.10 & $1.03^{* * *}$ & $0.64^{* * *}$ \\
\hline lnDistance $_{n i}$ & $-1.29^{* * *}$ & $-1.12^{* * *}$ & $-0.72^{* * *}$ & $-0.77^{* * *}$ \\
\hline Country & $\hat{S}_{i}$ & $\hat{S}_{i}$ & $\hat{S}_{i}$ & $\hat{S_{i}}$ \\
\hline AUSTRALIA & 0.000 & 0.000 & 0.000 & 0.000 \\
\hline AUSTRIA & -1.187 & -1.685 & -0.905 & -1.786 \\
\hline BELGIUM & -0.368 & -1.251 & 0.058 & -0.948 \\
\hline CANADA & 0.354 & -0.479 & 0.656 & -0.314 \\
\hline CZECH REPUBLIC & -2.334 & -1.792 & & \\
\hline DENMARK & -1.129 & -1.642 & -0.704 & -1.362 \\
\hline ESTONIA & -4.859 & -4.133 & & \\
\hline FINLAND & -0.618 & -0.885 & -0.515 & -1.264 \\
\hline FRANCE & 0.722 & 0.033 & 1.026 & 0.187 \\
\hline GERMANY & 1.369 & 0.603 & 1.686 & 0.711 \\
\hline GREECE & -2.592 & -3.255 & -2.360 & -3.037 \\
\hline HUNGARY & -2.278 & -2.607 & & \\
\hline IRELAND & -0.914 & -1.644 & & \\
\hline ITALY & 0.788 & 0.031 & 1.030 & 0.158 \\
\hline JAPAN & 2.514 & 1.410 & 2.806 & 1.719 \\
\hline KOREA & 1.078 & 0.026 & & \\
\hline NETHERLANDS & -0.070 & -0.813 & 0.381 & -0.438 \\
\hline NEW ZEALAND & -0.734 & -1.509 & -0.667 & -1.601 \\
\hline NORWAY & -1.553 & -1.982 & -1.186 & -1.692 \\
\hline POLAND & -2.031 & -2.351 & & \\
\hline PORTUGAL & -1.456 & -1.886 & -1.156 & -1.681 \\
\hline SLOVAKIA & -3.515 & -2.804 & & \\
\hline SLOVENIA & -3.837 & -4.220 & & \\
\hline SPAIN & -0.067 & -0.539 & 0.091 & -0.354 \\
\hline SWEDEN & -0.177 & -0.669 & 0.202 & -0.394 \\
\hline UNITED KINGDOM & 0.807 & 0.054 & 1.166 & 0.218 \\
\hline UNITED STATES & 2.982 & 2.075 & 3.200 & 2.182 \\
\hline Observations & 702 & 702 & 342 & 342 \\
\hline & 0.98 & & 0.94 & \\
\hline Pseudo $\mathrm{R}^{2}$ & & 0.88 & & 0.93 \\
\hline
\end{tabular}


Table 6: Welfare gains from trade

\begin{tabular}{|c|c|c|c|c|}
\hline & $\begin{array}{l}\pi_{n n} \\
(\%)\end{array}$ & $\begin{array}{c}G_{n} \\
(\%) \\
\theta=2.28\end{array}$ & $\begin{array}{c}G_{n}(p) \\
(\%) \\
\theta=4.91\end{array}$ & $\begin{array}{c}G_{n}(E K) \\
(\%) \\
\theta=3.60\end{array}$ \\
\hline \multicolumn{5}{|l|}{ Country } \\
\hline AUSTRALIA & 75.9 & 7.78 & 3.54 & 4.86 \\
\hline AUSTRIA & 47.8 & 20.05 & 8.85 & 12.27 \\
\hline BELGIUM & 5.6 & 30.74 & 13.25 & 18.50 \\
\hline CANADA & 51.0 & 17.65 & 7.84 & 10.84 \\
\hline DENMARK & 44.3 & 13.19 & 5.92 & 8.16 \\
\hline FINLAND & 68.7 & 2.51 & 1.16 & 1.58 \\
\hline FRANCE & 70.9 & 6.37 & 2.91 & 3.99 \\
\hline GERMANY & 74.2 & 4.01 & 1.84 & 2.52 \\
\hline GREECE & 65.5 & 17.28 & 7.68 & 10.62 \\
\hline ITALY & 80.3 & 4.19 & 1.92 & 2.63 \\
\hline JAPAN & 94.9 & 1.02 & 0.47 & 0.64 \\
\hline NETHERLANDS & 30.8 & 15.48 & 6.91 & 9.54 \\
\hline NEW ZEALAND & 66.8 & 11.55 & 5.20 & 7.17 \\
\hline NORWAY & 56.7 & 17.95 & 7.96 & 11.02 \\
\hline PORTUGAL & 62.2 & 20.23 & 8.93 & 12.38 \\
\hline SPAIN & 74.4 & 9.21 & 4.17 & 5.73 \\
\hline SWEDEN & 60.6 & 5.48 & 2.50 & 3.43 \\
\hline UNITED KINGDOM & 67.0 & 10.66 & 4.81 & 6.62 \\
\hline UNITED STATES & 88.9 & 2.94 & 1.35 & 1.85 \\
\hline
\end{tabular}

Notes: All the values are expressed in (\%) of GDP. 
Table 7: Impacts of a common manufacturing share on welfare

\begin{tabular}{lccc}
\hline \hline & $\alpha_{n}$ & $\begin{array}{c}\mathrm{G}_{n}(p) \\
\text { change in }(\%) \\
\alpha=0.2\end{array}$ & $\begin{array}{c}\mathrm{G}_{n}(p) \\
\text { change in }(\%) \\
\alpha=0.104\end{array}$ \\
\hline Country & & & -20.71 \\
\hline \hline AUSTRALIA & 0.130 & 54.43 & -12.85 \\
AUSTRIA & 0.118 & 73.55 & 153.93 \\
BELGIUM & 0.044 & 463.59 & -10.49 \\
CANADA & 0.115 & 77.69 & 44.45 \\
DENMARK & 0.072 & 188.73 & 232.43 \\
FINLAND & 0.031 & 550.66 & 20.85 \\
FRANCE & 0.086 & 136.18 & 65.29 \\
GERMANY & 0.063 & 222.33 & -43.36 \\
GREECE & 0.180 & 11.10 & 15.56 \\
ITALY & 0.090 & 124.52 & 10.00 \\
JAPAN & 0.094 & 112.04 & 82.21 \\
NETHERLANDS & 0.058 & 270.72 & -20.47 \\
NEW ZEALAND & 0.130 & 55.85 & -26.12 \\
NORWAY & 0.139 & 45.91 & -45.17 \\
PORTUGAL & 0.186 & 7.80 & -27.80 \\
SPAIN & 0.143 & 40.76 & 106.12 \\
SWEDEN & 0.051 & 305.85 & -14.64 \\
UNITED KINGDOM & 0.121 & 67.25 & -12.29 \\
UNITED STATES & 0.118 & 69.59 & \\
\hline Mean & 0.104 & & \\
\hline \hline
\end{tabular}

Notes: The changes in (\%) are with respect to the values reported in column 3 of Table 6 . 


\section{References}

Anderson, J. and Y. Yotov (2010a). The changing incidence of geography. American Economic Review 100, 2157-2186.

Anderson, J. and Y. Yotov (2010b). Specialization: Pro-and anti-globalizing, 1990-2002. Working Paper 16301, NBER.

Angrist, J. and J. Pischke (2009). Mostly harmless econometrics: An Empiricist's Companion. Princeton University Press.

Arkolakis, C., A. Costinot, and A. Rodriguez-Clare (2012). New trade models, same old gains. American Economic Review 102(1), 94-130.

Baker, M. and N. Fortin (2001). Occupational gender composition and wages in canada, 1987-1988. Canadian Journal of Economics 34(2), 345-376.

Barro, R. and J. W. Lee (2010). A new data set of educational attainment in the world, 1950-2010. Working Paper 15902, NBER.

Bils, M. and P. J. Klenow (2000). Does schooling cause growth? American Economic Review 90, 1160-1183.

Coe, D. T. and E. Helpman (1995). 'growth and human capital: Good data, good results. European Economic Review. 39, 859-887.

Cohen, D. and M. Soto (2001). International r\&d spillovers. OECD Development Centre Technical Papers No. 179..

Costinot, A., D. Donaldson, and I. Komunjer (2012). What goods do countries trade? a quantitative exploration of ricardo's ideas. Review of Economic Studies. 79(2), 581-608.

Dekle, R., J. Eaton, and S. Kortum (2007). Unbalanced trade. American Economic Review. 97(2), 351-355.

Dornbusch, R., S. Fischer, and P. A. Samuelson (1977). Comparative advantage, trade, and payments in a ricardian model with a continuum of goods. American Economic Review. 67, 823839.

Eaton, J. and S. Kortum (2002). Technology, geography and trade. Econometrica $70(5), 1741-1779$. 
Eaton, J. and S. Kortum (2012). Putting ricardo to work. Journal of Economic Perspectives 26(2), 65-89.

Eaton, J., S. Kortum, and S. Sotelo (2012). International trade: Linking micro and macro. Tech. Rep., NBER.

Erkel-Rousse, H. and D. Mirza (2002). Import price elasticities: reconsidering the evidence. Canadian Journal of Economics 35(2), 282-306.

Gourieroux, C., A. Monfort, and A. Trognon (1984). Pseudo maximum likelihood methods: Theory. Econometrica 52(3), 681-700.

Head, K. and T. Mayer (2002). Illusory border effects: Distance mismeasurement inflates estimates of home bias in trade. CEPR Discussion Papers 3327.

Head, K. and T. Mayer (2013). Gravity equations: Workhorse,toolkit, and cookbook. preliminary draft. Handbook of International Economics Vol.4..

Helpman, E., M. Melitz, and Y. Rubinstein (2008). Estimating trade flows: Trading partners and trading volumes. Quarterly Journal of Economics.

Inklaar, R. and M. Timmer (2008). Ggdc productivity level database: International comparisons of output, inputs and productivity at the industry level. Level,.Groningen Growth and Development Centre Research Memorandum GD-104.

Krugman, P. (1980). Scale economies, product differentiation, and the pattern of trade. American Economic Review. 70(5), 950-959.

Kyriacou, G. (1991). Level and growth effects of human capital. C. V. Starr Center Working Paper 91-26..

Macpherson, D. and B. Hirsch (1995). Wages and gender composition: why do womens jobs pay less? Journal of Labor Economics 13, 426-471.

Melitz, M. J. . (2003). The impact of trade on intra-industry reallocations and aggregate industry productivity. Econometrica. 71(6), 1695-1725.

Moulton, B. (1986). Random group effects and the precision of regression estimates. Journal of Econometrics 32, 385-397. 
Santos Silva, J. and S. Tenreyro (2006). The log of gravity. The Review of Economics and Statistics 88(4), 641-658.

Simonovska, I. and M. E. Waugh (2011). The elasticity of trade: Estimates and evidence. Working Paper 16796, NBER.

Summers, R. and A. Heston (1991). The penn world table (mark 5): An expanded set of international comparisons, 1950-1988. The Quarterly Journal of Economics 106, 327-368.

Waugh, M. E. (2010). International trade and income differences. American Economic Review 100(5), 2093-2124. 


\section{A Appendix}

\section{A.1 Derivation of the EK competitiveness equation}

In what follows I illustrate the steps which lead to equation (5)

The starting point is the trade share expression (equation (4p)):

$$
\frac{X_{n i}}{X_{n}}=\pi_{n i}=T_{i}\left(\frac{d_{n i} w_{i}^{\beta} p_{i}^{1-\beta} \gamma}{p_{n}}\right)^{-\theta}
$$

EK use this expression as it applies to home sales for country $n$ :

$$
\frac{X_{n n}}{X_{n}}=T_{n}\left(\frac{w_{n}^{\beta} p_{n}^{1-\beta} \gamma}{p_{n}}\right)^{-\theta}=T_{n}\left(\gamma w_{n}^{\beta} p_{n}^{-\beta}\right)^{-\theta}
$$

and country $i$ :

$$
\frac{X_{i i}}{X_{i}}=T_{i}\left(\frac{w_{i}^{\beta} p_{i}^{1-\beta} \gamma}{p_{i}}\right)^{-\theta}=T_{i}\left(\gamma w_{i}^{\beta} p_{i}^{-\beta}\right)^{-\theta}
$$

where $d_{n n}=d_{i i}=1$

The ratio leads to the following expression:

$$
\frac{\frac{X_{i i}}{X_{i}}}{\frac{X_{n}}{X_{n}}}=\frac{T_{i}\left(\gamma w_{i}^{\beta} p_{i}^{-\beta}\right)^{-\theta}}{T_{n}\left(\gamma w_{n}^{\beta} p_{n}^{-\beta}\right)^{-\theta}}=\frac{T_{i}}{T_{n}}\left(\frac{w_{i}}{w_{n}}\right)^{-\beta \theta}\left(\frac{p_{i}}{p_{n}}\right)^{\beta \theta}
$$

Through simple manipulations I obtain the following price ratio:

$$
\frac{p_{i}}{p_{n}}=\frac{w_{i}}{w_{n}}\left(\frac{T_{n}}{T_{i}}\right)^{\frac{1}{\beta \theta}}\left(\frac{\frac{X_{i i}}{X_{i}}}{\frac{X_{n n}}{X_{n}}}\right)^{\frac{1}{\beta \theta}}
$$

Which is equivalent to:

$$
\frac{p_{i}}{p_{n}}=\frac{w_{i}}{w_{n}}\left(\frac{T_{i}}{T_{n}}\right)^{-\frac{1}{\beta \theta}}\left(\frac{\frac{X_{i}}{X_{i i}}}{\frac{X_{n}}{X_{n n}}}\right)^{-\frac{1}{\beta \theta}}
$$


By normalizing trade share by the importer home sales we obtain:

$$
\frac{\frac{X_{n i}}{X_{n}}}{\frac{X_{n n}}{X_{n}}}=\frac{X_{n i}}{X_{n n}}=\frac{T_{i}}{T_{n}}\left(\frac{w_{i}}{w_{n}}\right)^{-\beta \theta}\left(\frac{p_{i}}{p_{n}}\right)^{-\theta(1-\beta)} d_{n i}^{-\theta}
$$

By substituting the price ratio into the equation above I obtain the tranformed EK trade equation (5).

\section{A.2 1990's EK model replication}

Table 9 reports the second stage results of the EK empirical analysis replication for 1990. Since EK in their original paper use different data sources for instrumental variables, geographic barriers and technology, for the purpose of this paper it's relevant to check whether the data utilised in this analysis lead to estimates which are consistent with the EK results 30

The estimated exporter fixed effects are obtained from a first stage regression whose structure is very similar to the EK specification: the estimations are from the same sample of 19 OECD countries, and the same bloc dummies (EFTA and $\mathrm{EC}$ ) are included to measure the RTA effect. In addition, I calculated $\beta=0.21$, which is exactly the EK result. In contrast to the original EK specification, the first stage regression is estimated using OLS with robust standard errors, while distance is measured as the log of weighted distance as commonly found in the literature ${ }^{31}$ Table 8 reports the first-stage estimates. In line with EK results the estimates show that Japan is the most competitive country in 1990, while Belgium is at the same time the most open and the least competitive country of the sample. All the gravity controls have the expected sign with the exception of common border.

\footnotetext{
${ }^{30}$ EK utilized average years of schooling for 1985 from Kyriacou (1991), stocks of research for each country from Coe and Helpman (1995) and aggregate workforce, which is used as instrument for wages, from Summers and Heston (1991). Kyriacou (1991) estimates average years of schooling in the labor force as an index of human capital stock. As for R\&D data, Coe and Helpman (1995) estimate stocks of research using the perpetual inventory method (assuming a depreciation rate of five percent) to add up real R\&D investment by business enterprises. In Summers and Heston (1991) the labor force participation rate and total workforce, are given implicitly by the values of gross domestic product per capita and per worker.

${ }^{31} \mathrm{EK}$ estimate the regression by generalized least squares (GLS). They also divide distance in 6 intervals, all included in their first stage specification (p.1762).
} 
Table 8: First stage 1990

\begin{tabular}{lcccc}
\hline Variable & & & Coefficient & se \\
\hline Shared border & & $-\theta$ contig $_{n i}$ & -0.30 & $(0.33)$ \\
Shared language & & $-\theta$ lang $_{n i}$ & $0.68^{* * *}$ & $(0.17)$ \\
EC & & $-\theta \mathrm{EC}_{n i}$ & 0.26 & $(0.18)$ \\
EFTA & & $-\theta \mathrm{EFTA}_{n i}$ & 0.32 & $(0.25)$ \\
Distance & $\hat{S}_{i}^{\prime}$ & $-\theta d_{n i}$ & $-1.05^{* * *}$ & $(0.07)$ \\
\hline Country & 2.29 & $(0.25)$ & -0.70 & $(0.27)$ \\
\hline AUSTRALIA & 0.43 & $(0.15)$ & -1.24 & $(0.40)$ \\
AUSTRIA & -1.86 & $(0.14)$ & 3.36 & $(0.24)$ \\
BELGIUM & 1.98 & $(0.21)$ & -0.78 & $(0.24)$ \\
CANADA & 0.00 & $()$. & 0.43 & $(0.23)$ \\
DENMARK & 1.58 & $(0.17)$ & -1.28 & $(0.19)$ \\
FINLAND & 3.07 & $(0.13)$ & -1.80 & $(0.22)$ \\
FRANCE & 3.94 & $(0.14)$ & -1.73 & $(0.22)$ \\
GERMANY & -0.04 & $(0.14)$ & -0.94 & $(0.28)$ \\
GREECE & 3.24 & $(0.35)$ & -2.57 & $(0.23)$ \\
ITALY & 5.85 & $(0.18)$ & -3.20 & $(0.29)$ \\
JAPAN & -0.14 & $(0.14)$ & 1.72 & $(0.22)$ \\
NETHERLANDS & 0.85 & $(0.25)$ & 0.75 & $(0.29)$ \\
NEW ZEALAND & 0.23 & $(0.17)$ & 0.00 & $()$. \\
NORWAY & 0.82 & $(0.21)$ & -0.82 & $(0.27)$ \\
PORTUGAL & 2.20 & $(0.14)$ & -2.19 & $(0.27)$ \\
SPAIN & 2.02 & $(0.17)$ & -0.87 & $(0.19)$ \\
SWEDEN & 2.83 & $(0.14)$ & -1.42 & $(0.25)$ \\
UNITED KINGDOM & 5.60 & $(0.19)$ & -2.49 & $(0.25)$ \\
UNITED STATES & 5.60 & & Root MSE & 0.59 \\
\hline \hline Observations & 342 & & & \\
$\mathrm{R}^{2}$ & 0.96 & & & \\
\hline Notes: robust standard errors in parentheses. & & & \\
${ }^{*} p<0.05,{ }^{*}{ }^{\prime} p<0.01{ }^{* * *} p$ & $p<0.001$ & & & \\
& & & &
\end{tabular}


Table 9: EK Competitiveness equation 1990 - Barro Lee/Cohen Soto

\begin{tabular}{lcccc}
\hline \hline & OLSbl & 2SLSbl & OLScs & 2SLScs \\
\hline lnWages $_{i}$ & $-2.46^{* *}$ & $-3.40^{* *}$ & $-2.90^{* *}$ & $-4.03^{* * *}$ \\
& $(0.90)$ & $(1.34)$ & $(1.25)$ & $(1.29)$ \\
& & & & \\
$\operatorname{lnR} \& \mathrm{D}_{i}$ & $1.22^{* * *}$ & $1.34^{* * *}$ & $1.19^{* * *}$ & $1.26^{* * *}$ \\
& $(0.15)$ & $(0.17)$ & $(0.13)$ & $(0.12)$ \\
$1 / \mathrm{H}_{i}$ & & & & \\
& 6.71 & 7.10 & -1.52 & -7.44 \\
& $(6.03)$ & $(7.59)$ & $(9.67)$ & $(10.28)$ \\
Constant & 20.99 & $29.89^{* *}$ & 26.09 & $37.52^{* *}$ \\
& $(8.25)$ & $(12.00)$ & $(12.58)$ & $(12.74)$ \\
\hline Observations & 19 & 19 & 19 & 19 \\
$\mathrm{R}^{2}$ & 0.78 & 0.76 & 0.79 & 0.77 \\
Root MSE & 1.02 & 1.06 & 1.00 & 1.04 \\
\hline \hline Notes: robust standard errors in parentheses. & & & \\
${ }^{*} p<0.05,{ }^{* *} p<0.01,{ }^{* * *} p<0.001$ & & & \\
& & & &
\end{tabular}

The $\hat{S}_{i}{ }^{\prime}$ are then regressed on two proxies for technology (R\&D expenditures and average years of education) and wages corrected for worker quality. The secondstep regression is estimated twice, using different database for education: first Barro and Lee (2010), then Cohen and Soto (2001). Since human capital is used to correct both wages and labour force for worker quality, and it also appears as a proxy for technology, a different database for education could lead to substantial differences in the measure of the elasticity of trade ${ }^{32}$ The structure of the second stage specification is maintained identical to the original EK competitiveness equation: the inverse of the average years of schooling is used as a proxy for human capital and the same EK instruments for wages have been used.

As can be observed from Table 9, the elasticity of trade obtained through 2SLS ranges between 4.03 and 3.40 which I view as reassuring, since both estimates are quite close to 3.60. Using a different database for education affects the estimation of the elasticity of trade: the difference between the two 2SLS estimates is around 0.6 . Finally, as in EK, the effect of education on country $i$ competitiveness is not statistically significant and only Cohen and Soto (2001) data give the expected sign; as for R\&D, both effects are similar in magnitude to the EK results 33

\footnotetext{
${ }^{32}$ This kind of experiment couldn't be conducted for the whole sample of 27 countries for 1997, since some of the data on education needed for the comparison are not available in Cohen-Soto database.

${ }^{33}$ The first stage results obtained using OLS with robust standard errors are almost identical to
} 


\section{A.3 One-step analysis}

One-step specification. Head and Mayer (2013) identified in the literature 744 gravity based estimates of trade elasticity: many of these coefficients have been estimated through a one-step procedure. In EK, for instance, two of the three methodologies implemented to obtain an estimate of trade elasticity are one-step. In what follows I estimate the same EK competitiveness equation for 1997 using a one-step procedure. By plugging the determinants of $S_{i}{ }^{\prime}$ into the EK bilateral trade equation, I obtain the following one-step specification:

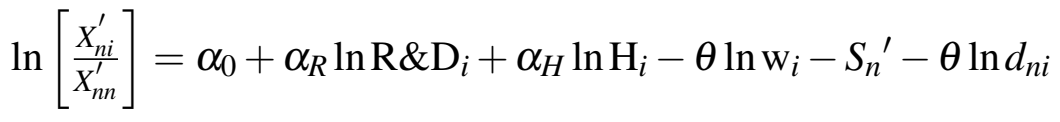

$$
\begin{aligned}
& -\theta \operatorname{lang}_{n i}-\theta \operatorname{contig}_{n i}-\theta \mathrm{RTA}_{n i}+\delta_{n i}^{1}+\delta_{n i}^{2}+u_{i}
\end{aligned}
$$

One-step and two-step methodologies are not equivalent. According to the literature, there may be substantial differences between one-step and two-step procedures and generally the two-step technique is preferred. These differences involve both (i) the magnitude as well as (ii) the standard errors of the coefficients.

(i) Baker and Fortin (2001) showed that the one-step methodology may lead to biases in the coefficients if and only if the second-stage error term $u_{i}$ is not orthogonal to the one-step regressors, namely geographic barriers, exporter and importer fixed effects ${ }^{34}$ Otherwise, all else being equal, the two procedures should lead to similar estimates under the assumption that $u_{i}$ is truly a random effect. In the equation above, the residual $u_{i}$ captures the impact on country $i$ 's competitiveness of variables other than wages and technology: this effect in the one-step procedure should be incorporated in the error component that affects trade one way. Thus, if the assumption of $\delta_{n i}$ consisting of two components both orthogonal to the first stage regressors is correct, $u_{i}$ is also orthogonal to the one step regressors and the two procedures should lead to similar estimates.

the ones obtained using WLS, which is just a special case of the more general estimating technique GLS. As a consequence, both WLS and OLS fixed effects coefficients lead to identical measures of $\theta$. These results are available upon request.

${ }^{34}$ The assumption I made for the competitiveness regression implies that $u_{i}$ is orthogonal to the competitiveness determinants 
Table 10: One-step estimations

\begin{tabular}{|c|c|c|c|c|}
\hline & OLS & 2 SLS & OLS & $2 \mathrm{SLS}$ \\
\hline lnWages $_{i}$ & $\begin{array}{l}-3.99 \\
(2.73)\end{array}$ & $\begin{array}{c}-5.44 \\
(3.51)\end{array}$ & $\begin{array}{l}-0.00 \\
(0.16)\end{array}$ & $\begin{array}{c}-1.88 \\
(1.25)\end{array}$ \\
\hline $\operatorname{lnR} \& \mathrm{D}_{i}$ & $\begin{array}{c}1.70^{* * *} \\
(0.39)\end{array}$ & $\begin{array}{c}1.83^{* * *} \\
(0.41)\end{array}$ & $\begin{array}{c}0.83^{* * *} \\
(0.06)\end{array}$ & $\begin{array}{c}1.67^{* * *} \\
(0.29)\end{array}$ \\
\hline $1 / \mathrm{H}_{i}$ & $\begin{array}{c}19.16 \\
(14.98)\end{array}$ & $\begin{array}{c}12.43 \\
(16.10)\end{array}$ & $\begin{array}{c}4.76 \\
(4.90)\end{array}$ & $\begin{array}{c}36.58 \\
(18.01)\end{array}$ \\
\hline Constant & $\begin{array}{c}20.88 \\
(24.05)\end{array}$ & $\begin{array}{c}34.00 \\
(33.07)\end{array}$ & $\begin{array}{c}0.82 \\
(1.57)\end{array}$ & $\begin{array}{c}2.16 \\
(8.23)\end{array}$ \\
\hline Observations & 342 & 342 & 702 & 702 \\
\hline $\mathrm{R}^{2}$ & 0.83 & 0.83 & 0.86 & 0.82 \\
\hline Root MSE & 1.85 & 1.87 & 0.78 & 2.03 \\
\hline
\end{tabular}

(ii) Since country characteristics are likely to be correlated within groups, the estimated coefficients may show a much lower variance in the one-step procedure when using heteroskedasticity consistent White robust standard errors. Moulton (1986) argues that a possible cause for relatively lower standard errors in the one-step procedure might be a source of downward bias due to the correlation of individual error terms within groups; this may lead to serious mistakes in statistical inference. This bias derives from using grouped data in an individual level regression where groups are not allowed to be treated as fixed parameters. To quantify the magnitude of this bias, Macpherson and Hirsch (1995) found that the single step estimation produced coefficients with standard errors ten times lower compared to the standard errors obtained through the two-step procedure. To correct for the one-step Moulton bias, I use standard errors clustered by country $i$. The number of clusters is crucial to establish whether or not the standard cluster adjustment is reliable. Angrist and Pischke (2009) argue that with few clusters there's a tendency to underestimate the intraclass correlation in the Moulton problem. However, there's not a specific number of clusters considered as a threshold which separates a reliable from an unreliable standard cluster adjustment. Angrist and Pischke (2009) propose 42 which is way beyond the number of clusters of the whole sample. 35

\footnotetext{
${ }^{35}$ The same authors seem a bit skeptical about this number, since the literature provides exam-
} 
The one-step specification is estimated with 2SLS. Even though this methodology will lead to biased coefficients for the arguments expressed by Santos Silva and Tenreyro (2006), this is the best way of comparing the one-step procedure with the two-step technique since the second stage results in Section 4.1 are obtained with 2SLS even in the case when $S_{i}^{\prime}$ are from PPML.

Table 10 shows the one-step results. The same instruments for wages are employed as in the two-step approach. As it emerges from the estimates, the measure of $\theta$ is again larger when instrumenting. The one-step results seem partly consistent with the assumption of orthogonality of $\delta_{n i}$, since for the whole sample the 2SLS estimation of $\theta$ is very close in magnitude to the correspondent two-step measure reported in Table 1. The difference is only around 0.13 . However, the measure of $\theta$ obtained from the smaller EK sample shows a discrepancy of 0.88 , which indicates a possible bias in the one-step estimation.

Table 11: Ratios of standard errors

\begin{tabular}{lcccc}
\hline \multicolumn{5}{c}{ Table 11: Ratios of standard errors } \\
\hline \hline $\ln$ 19c & $27 \mathrm{c}$ & $19 \mathrm{c}$ & $27 \mathrm{c}$ \\
$\operatorname{lnR}_{i} \& \mathrm{D}_{i}$ & 3.42 & 4.17 & 3.31 & 5.29 \\
$1 / \mathrm{H}_{i}$ & 3.45 & 3.95 & 3.35 & 5.20 \\
Constant & 2.32 & 4.03 & 3.10 & 5.43 \\
\hline \hline & 3.02 & 3.24 & 2.85 & 5.00 \\
\hline Notes:columns 1 and 2 report clustered by exporter se/robust se \\
Notes:columns 3 and 4 report two-step se/robust se \\
${ }^{*} p<0.05,{ }^{* *} p<0.01,{ }^{* * *} p<0.001$
\end{tabular}

To correct for the one-step Moulton bias, I use standard errors clustered by country $i$. The first two columns of Table 11 reports the ratio between standard errors clustered by exporter and White robust standard errors for the one-step procedure. The ratios indicate that on average standard errors are between three and four times higher when clustered by exporter. The ratios between two-step and onestep White robust standard errors are showed in columns 3 and 4: the evidence indicates that the ratios are substantially lower than the correspondent measures found in Macpherson and Hirsch (1995).

As expected, the one-step standard errors clustered by exporter are closer to the ones obtained with the two-step procedure. This is true especially for the EK

ples where clustered standard errors are reasonably good even in a scenario with 10 groups. 
sample, as the first and third columns of Table 11 show very similar ratios for all coefficients. The ratios reported in the second and fourth columns show a larger discrepancy. This result is a bit surprising, since according to Angrist and Pischke (2009) a higher number of clusters should imply a reduction in the Moulton bias because of a lower intraclass correlation. My results seem to go in the opposite direction. 